\title{
AEROBIC BIODEGRADABILITY ASSESSMENT OF PHARMACEUTICAL WASTEWATER FROM INDUSTRIAL PRODUCTION OF ANTIBIOTICS
}

\author{
R. B. P. MARCELINO ${ }^{1}$, A. L. EMRICH ${ }^{1}$, L. GONÇALVES ${ }^{1}$, C. C. de AMORIM ${ }^{1}$, M. M. D. \\ $\mathrm{LEÃO}^{1}, \mathrm{R} . \mathrm{P} . \mathrm{LOPES}^{2}$ \\ ${ }^{1}$ Universidade Federal de Minas Gerais, Departamento de Engenharia Sanitária e Ambiental \\ ${ }^{2}$ Universidade Federal de Viçosa, Departamento de Química \\ E-mail: rafaelaportela@gmail.com
}

\begin{abstract}
Antibiotics are considered emerging environmental issues and the presence of its traces in the environment can induce the development of resistant pathogens and promote allergies. Biological treatment is the most widely used method for industrial wastewater treatment, but it has been proved inefficient for the removal of all hazardous constituents of pharmaceutical products. In this context, the aim of this study is to evaluate the potential of aerobic biodegradation of organic matter present in real antibiotics production effluent using the method proposed by Zahn - Wellens. The organic matter degradation was monitored through periodic analysis of total organic carbon (TOC). After 28 days, the reactor achieved more than $80 \%$ of TOC removal, characterizing the wastewater as biodegradable, according to the used methodology.
\end{abstract}

\section{INTRODUCTION}

Emerging pollutants are groups of compounds without specific legal regulations whose toxic effects to the environment and human health coupled with high occurrence make them subject to future regulations (MIRALLES-CUEVAS et al., 2013). This group includes various types of globally widespread organic compounds, such as pesticides, dyes, pharmaceuticals, personal care products, polymers and plastics. Most of the pharmaceuticals used are excreted in an unchanged or only partially metabolized form and end up as such in municipal waste water and in the environment.

Antibiotics are chemical, natural or synthetic pharmaceuticals that can eliminate or prevent the multiplication of bacteria. These drugs have been extensively used in human and veterinary medicine to treat diseases caused by bacteria and, in some cases, to prevent bacterial infections. They are also used as growth promoters in animals that are part of the food industry, and as pesticides for controlling bacterial infections in crop fields, particularly cereals. Therefore, they are abundant contaminants in the environment (KIM et al., 2013). The effluents from the production of antibiotics are considered emerging environmental problems due to their refractory characteristics and toxicity to the environment, even in low concentrations. The presence of 
traces of such pharmaceuticals in the environment can induce the development of antibioticresistant pathogens, triggering serious problems for human and animal health (MASCOLO et al., 2010). It is estimated that about half of the pharmaceutical effluent produced in the world is thrown into water bodies without any treatment (DEEGAN, 2011). When these wastewaters are treated, there may be employed inefficient techniques for the degradation of recalcitrant and dangerous compounds present.

Biological treatment consists in decomposing the water-soluble and non-volatile organic matter through microorganism's oxidation and/or fermentation in controlled and specially designed reactors. There are two types of biological treatment: aerobic, in which microorganisms degrade organic substances through oxidation processes with the use of oxygen as the electron acceptor; and anaerobic, in which anaerobic microorganisms decompose organic substances through oxidation with electron acceptors different than oxygen (sulfur; nitrate, etc.) or fermentation processes. Biological treatment is the most common and economical method of wastewater treatment used, however, is has been proved ineffective for the removal of all potentially hazardous constituents of pharmaceutical effluents (MONTEAGUDO et al., 2013; PÉREZ-MOYA et al., 2010).

In another hand, advanced oxidations processes are widely used for treatment of toxic or non-biodegradable wastewaters, but the intensity and duration of those reactions influence directly on the treatment costs and mineralization efficiency. Hence, special attention must be paid to the biodegradability determination of the mixture of intermediates generated during advanced oxidation treatment of recalcitrant and dangerous wastewaters, which relies on biodegradability tests (BALLESTEROS MARTÍN et al., 2010). Therefore, biodegradability is a key parameter in the hazard assessment of chemicals and wastewaters. High biodegradability implies a reduced tendency to bioaccumulate or to persist in the environment (STOLTE et al., 2012).

In order to assess the biodegradability of wastewater, several methods (Zahn-Wellens test, $\mathrm{BOD}_{5} / \mathrm{COD}$ ratio, respirometry test, Pseudomonas putida bioassay) were proposed by international organizations, such as OECD and ISO. These biodegradation assessments are divided into three major groups: tests on ready biodegradability, tests on inherent biodegradability and simulation tests. Zahn-Wellens is an inherent biodegradability test that evaluates the potential biodegradability of water-soluble, non-volatile organic substances exposed to high concentrations of microorganisms and nutrients in 28 days (BALLESTEROS MARTÍN et al., 2010; PAGGA, 1997).

The Zahn-Wellens test forecasts the degradation behavior of a wastewater in an activated sludge treatment plant, since the experimental conditions are similar to this process. Nevertheless, humble biodegradability results obtained in an inherent biodegradability test are considered sufficiently indicative for poor biodegradability, but positive results are not necessarily predictive of biodegradability under real environmental conditions, a significant overestimation of the removal extent was reported in literature (MASCOLO et al., 2010). Ballesteros Martin et al. (2010) compared four biodegradability tests (Pseudomonas putida bioassay, Zahn-Wellens test, 
$\mathrm{BOD}_{5} / \mathrm{COD}$ and respirometry assay) to determine the biodegradability enhancement of a treated pesticides mixture taking into account repeatability and precision of each biodegradability test. The authors concluded that $P$. putida and Zahn-Wellens tests showed higher repeatability and precision.

In this context, the aim of this study is to evaluate the potential of aerobic biodegradation of organic matter present in real antibiotics production wastewater using the method proposed by Zahn - Wellens (OECD, 1992) with the use of recirculation sludge from the activated sludge reactor of the municipal Wastewater Treatment Plant (WWTP) of Ribeirão Arrudas in Belo Horizonte, as inoculum.

\section{MATERIAL AND METHODS}

\subsection{Biomass}

The sludge used as biomass source was collected at the recirculation step of the biological reactor in activated sludge system of the WWTP of Ribeirão Arrudas in Belo Horizonte, Brazil. The sludge was stored in the fridge at $5^{\circ} \mathrm{C}$ until used and pre-conditioned to the experimental conditions by sedimentation and several tap water washing prior to use in order to concentrate the biomass and reduce the TOC background. Sludge biomass concentration $(250 \pm 4) \cdot 10^{-1} \mathrm{~g} \cdot \mathrm{L}^{-1}$ was determined gravimetrically (APHA-AWWA-WEF, 1992) by measuring volatile suspended solids (VSS).

\subsection{Wastewater}

The wastewater sample used in this work was obtained at an antibiotics production plant in a pharmaceutical industry in Brazil. The effluent is an aqueous mixture of cleaning waters, cleaning products, antibiotics, solvents and intermediates. At the time of sample collection, the industry produced amoxicillin, so this antibiotic was monitored after the biodegradation assessment. The physical-chemical characteristics of the pharmaceutical wastewater were assessed and are reported in Table 1.

\subsection{Chemicals}

Sodium hydroxide and sulfuric acid were used in the biological reactor in order to keep the $\mathrm{pH}$ in a neutral threshold $(6,5-7,5)$. All the chemicals used for the wastewater characterization analysis and for the preparation of the mineral nutrients solutions were at least $>98 \%$ pure (analytical grade). The amoxicillin used in HPLC determinations was provided by the pharmaceutical industry. 
Table 1 - Physical-chemical characteristics of the investigated pharmaceutical wastewater

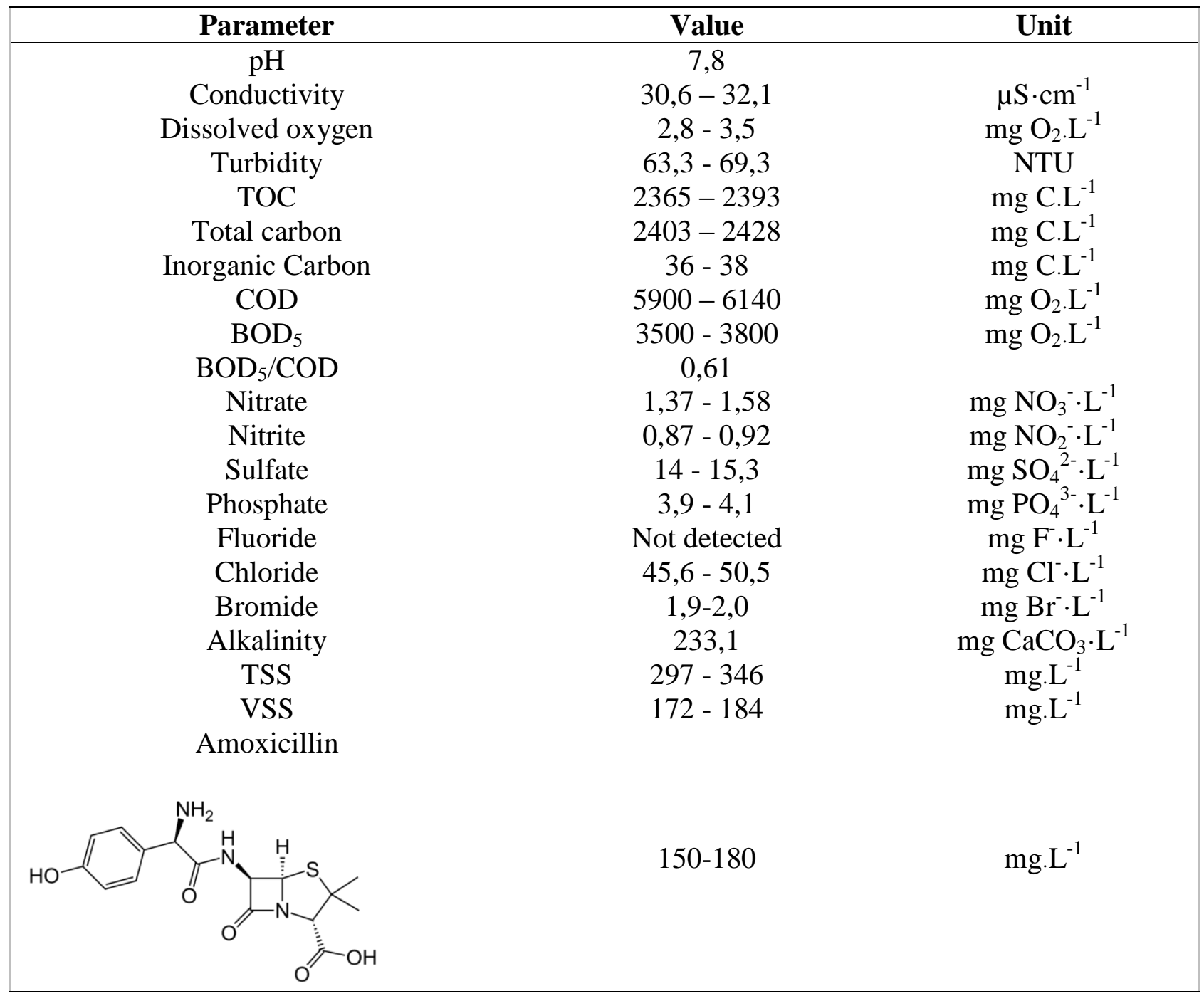

\subsection{Analytical techniques and procedures}

The organic matter degradation was monitored through periodic sample collection, filtration with quantitative filter paper $125 \mathrm{~mm} \mathrm{C} 40$ to remove the suspended solids (sludge) and subsequent analysis of total organic carbon (TOC) in TOC-V CPN equipment (Shimadzu). The specific degradation of amoxicillin after the biodegradability experiments was followed by HPLC (Agilent Technologies Model 1260 Infinity) equipped with a reverse-phase Zorbax Eclipse Plus® C18 (4.6 X $150 \mathrm{~mm}, 5.0 \mu \mathrm{m})$. The mobile phase was methanol:water $(55: 45, \mathrm{v} / \mathrm{v})$ at isocratic elution. The flow was $0.750 \mathrm{~mL} \cdot \mathrm{min}^{-1}$ and the monitored wavelength was $210 \mathrm{~nm}$. The aliquots were filtered through $0.20 \mu \mathrm{m}$ syringe filters (Millexs-GN, 25mm, Millipore) before HPLC injection. The injection volume was $20 \mu \mathrm{L}$ and the total run time was 10 minutes. 


\section{9 a 22 de outubro de 2014 \\ Florianópolis/SC}

\subsection{Aerobic biodegradation}

The aerobic biodegradability assays were performed accordingly to the Zahn-Welles test methodology (OECD, 1992) with high nutrient and biomass concentration. The biodegradation was also assed adapting the method for the use of the high organic carbon wastewater (TOC $\left.\sim 2400 \mathrm{mg} \cdot \mathrm{L}^{-1}\right)$. The organic matter degradation was monitored through periodic analysis TOC. Test A (called diluted wastewater) was performed using a diluted wastewater so that the initial TOC was in the organic matter threshold imposed by Zahn-Wellens method (initial TOC 217 $\mathrm{mg} \cdot \mathrm{L}^{-1}$ ). Test $\mathrm{B}$ (called pure wastewater) was performed with the pharmaceutical wastewater without prior dilution (the mineral nutrients solution used in the reactor produced a small dilution) and initial TOC was around $1720 \mathrm{mg} \cdot \mathrm{L}^{-1}$.

A micro and macro nutrients mineral solution was prepared accordingly to the ZahnWellens methodology. $500 \mathrm{~mL}$ of this nutrients solution was added to each reactor. In order to obtain around $0,6 \mathrm{~g} \cdot \mathrm{L}^{-1}$ of biomass in the reactors, $50 \mathrm{~mL}$ of the pre-conditioned sludge was added to each vessel. The control and blank experiments were prepared using glucose as carbon source (initial TOC $200 \mathrm{mg} \cdot \mathrm{L}^{-1}$ ), which is highly biodegradable, and distilled water, respectively. Then, the mineral nutrients and the activated sludge were also added. Two litters Erlenmeyer vessels were used as reactors and the test was performed under aeration with the use of aquarium aerators and kept in the dark (aluminum sheet exterior cover) at room temperature 23-29 ${ }^{\circ} \mathrm{C}$ for 28 days. Samples were taken at appropriate regular time intervals and TOC was determined. At each sampling, loss of volume due to evaporation was mitigated with distilled water and $\mathrm{NaOH}$ and $\mathrm{H}_{2} \mathrm{SO}_{4}$ solutions were used to keep the $\mathrm{pH}$ in the reactors in a neutral threshold $(6,5-7,5)$.

The percentage of biodegradation $\left(D_{t}\right)$ at time $t$ was determined by the equation 1 :

$$
D_{t}=\left[1-\left(\frac{C_{t}-C_{B}}{C_{A}-C_{B A}}\right)\right] \times 100
$$

where $\mathrm{C}_{\mathrm{A}}$ and $\mathrm{C}_{\mathrm{BA}}$ are the TOC $\left(\mathrm{mg} \cdot \mathrm{L}^{-1}\right)$ in the sample and in the blank, respectively, measured 3 $h$ after starting the experiment, and $C_{t}$ and $C_{B}$ are the TOC $\left(\mathrm{mg} \cdot \mathrm{L}^{-1}\right)$ in the sample and in the blank, respectively, measured at the sampling time $\mathrm{t}$. The wastewater samples are considered biodegradable by Zahn-Wellens methodology when $\mathrm{D}_{\mathrm{t}}$ is higher than $70 \%$.

\section{RESULTS AND DISCUSSION}

Figure 1 shows the average evolution of the measured TOC in all the reactors investigated during the 28 days of biodegradation by Zahn-Wellens methodology. It is possible to note that the diluted wastewater (A) TOC decreased faster than the pure wastewater (B). The percentage of biodegradation $\left(D_{t}\right)$ for the diluted wastewater $(A)$ and for the pure wastewater (B) was determined by equation 1 and is represented in Figure $1 \mathrm{~b}$. The wastewater samples are considered biodegradable when $\mathrm{D}_{\mathrm{t}}$ is higher than $70 \%$. According to this test, both diluted and pure 
wastewaters can be considered biodegradables effluents. It can be noted that the diluted wastewater achieved more than $80 \%$ of biodegradation after the first day of reaction, while the raw wastewater needed 6 days to achieve biodegradability.

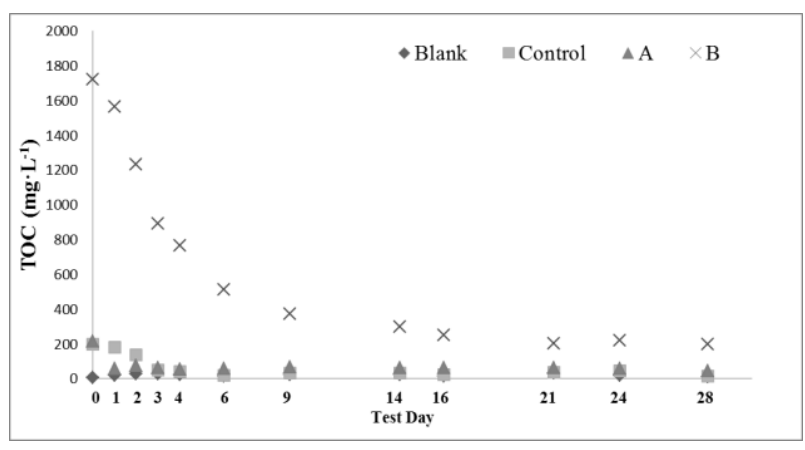

(a)

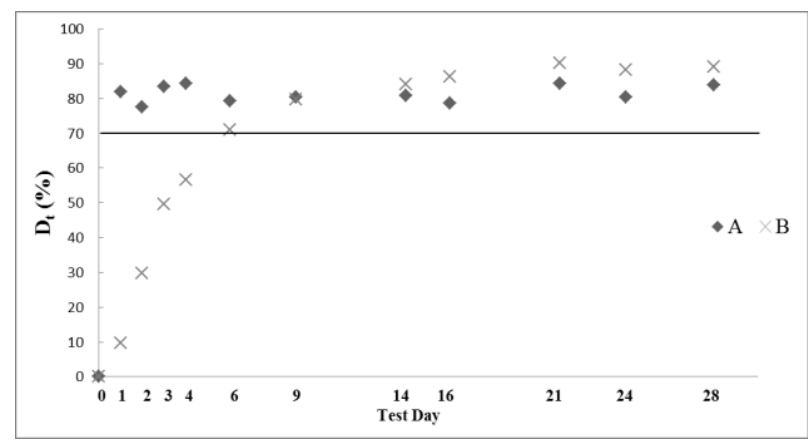

(b)

Figure 1(a) - TOC evolution in the blank, control, A- diluted wastewater - and B - pure wastewater reactors during the 28 days of biodegradation by Zahn-Wellens methodology.

Figure 1(b) - Zahn-Wellens percentage of biodegradation $\left(D_{t}\right)$ for the diluted wastewater (A) and for the pure wastewater (B).

HPLC monitoring (Figure 2) showed that more than $80 \%$ of the amoxicillin present in the pure wastewater $(B)$ was destructed after the biodegradation reaction ( 28 days).

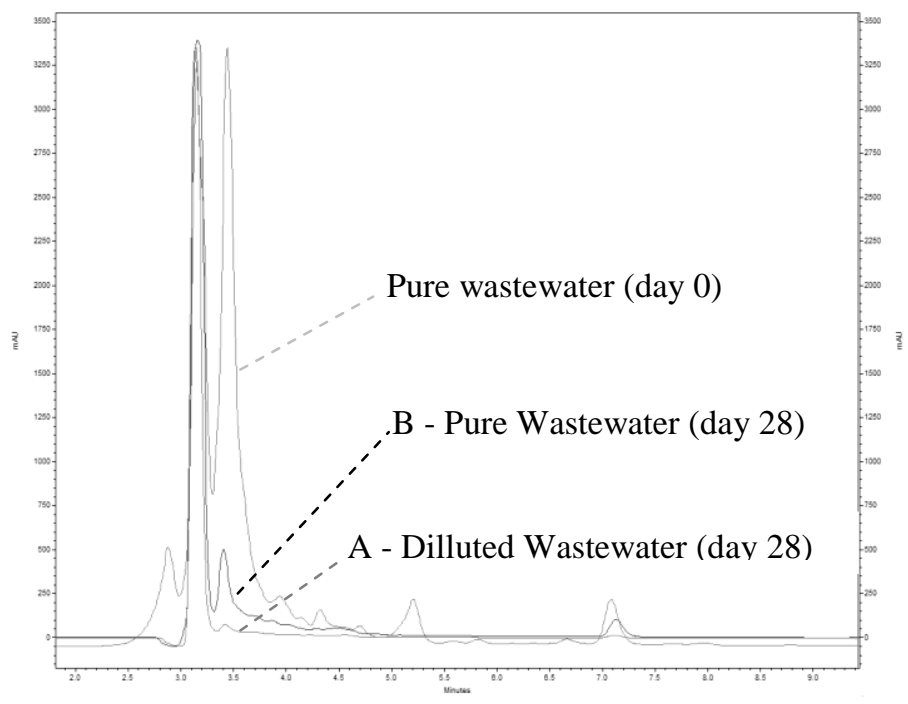

Figure 2 - HPLC chromatograms of the pure wastewater at day 0 and at day 28 for the diluted wastewater (A) and for the pure wastewater (B). 
It is noteworthy that even though the used methodology classifies this wastewater as biodegradable, positive results are not necessarily predictive of biodegradability under real treatment conditions. Some researches, such as Mascolo et al. (2010), reported that a significant overestimation of the removal extent can be assumed by this method. A real wastewater treatment plant may not receive diluted effluents, may not have all the nutrients added in this experiment and may not have all the residence time proposed by Zahn-Wellens methodology.

Moreover, the organic matter that was not biodegraded in the 28 days experiment can be more toxic and more dangerous than the raw wastewater. Furthermore, the use of biological treatment for antibiotics containing wastewater can induce the development of antibiotic-resistant pathogens, whose resistance genes can be transmitted through many generations, triggering serious problems for human and animal health.

\section{CONCLUSIONS}

It can be concluded that the real antibiotics production wastewater investigated in this work is considered biodegradable by the Zahn-Wells test (both diluted and raw wastewater) and that biomass could degrade more than $80 \%$ of the antibiotics present in the raw wastewater. However, it is noteworthy to say that significant overestimation of the removal extent can be assumed by this method and that the use of biological treatment for antibiotics containing wastewater can induce the development of antibiotic-resistant pathogens, triggering serious problems for human and animal health.

\section{ACKNOWLEDGEMENT}

The authors thank the Foundation for Research Support of the State of Minas Gerais FAPEMIG, CNPQ and Iara Project (BNDES/UFMG) for the financial support.

\section{REFERENCES}

BALLESTEROS MARTÍN, M. M. et al. A comparative study of different tests for biodegradability enhancement determination during AOP treatment of recalcitrant toxic aqueous solutions. Ecotoxicology and Environmental Safety, v. 73, n. 6, p. 1189-1195, 2010.

DEEGAN, A. M. S., B.; NOLAN, K.; URELL, K.; OELGEMÖLLER, M.; TOBIN, J.; MORRISSEY, A. Treatment options for wastewater effluent from pharmaceutical companies. Int. J. Environ. Sci. Tech., v. 8, n. 3, p. 649-666, 2011. 
KIM, H. Y. et al. Reduction of toxicity of antimicrobial compounds by degradation processes using activated sludge, gamma radiation, and UV. Chemosphere, v. 93, n. 10, p. 2480-2487, 2013.

MASCOLO, G. et al. Biodegradability of pharmaceutical industrial wastewater and formation of recalcitrant organic compounds during aerobic biological treatment. Bioresource Technology, v. 101, n. 8, p. 2585-2591, 2010.

MIRALLES-CUEVAS, S. et al. Combined nanofiltration and photo-Fenton treatment of water containing micropollutants. Chemical Engineering Journal, v. 224, n. 0, p. 89-95, 2013.

MONTEAGUDO, J. M. et al. Optimization of pharmaceutical wastewater treatment by solar/ferrioxalate photo-catalysis. Journal of Environmental Management, v. 128, n. 0, p. 210-219, 2013.

OECD. Test No. 302B: Inherent Biodegradability: Zahn-Wellens/ EVPA Test. OECD Publishing, 1992.

PAGGA, U. Testing biodegradability with standardized methods. Chemosphere, v. 35, n. 12, p. 2953-2972, 1997.

PÉREZ-MOYA, M. et al. Characterization of the degradation performance of the sulfamethazine antibiotic by photo-Fenton process. Water Research, v. 44, n. 8, p. 2533-2540, 2010.

STOLTE, S. et al. Ionic liquids as lubricants or lubrication additives: An ecotoxicity and biodegradability assessment. Chemosphere, v. 89, n. 9, p. 1135-1141, 2012.

TRAUTWEIN, C.; KÜMMERER, K.eMETZGER, J. W. Aerobic biodegradability of the calcium channel antagonist verapamil and identification of a microbial dead-end transformation product studied by LC-MS/MS. Chemosphere, v. 72, n. 3, p. 442-450, 2008. 